\title{
Improving Patient Safety through a Multi-faceted Internal Surveillance Program
}

Anne Matlow, Polly Stevens, Lynn Urmson and Rick Wray

\begin{abstract}
Surveillance, a method used in epidemiology to study the incidence, distribution and control of disease, is an important means of gathering and analyzing information that can be used as needed to effect change. Surveillance has been an important component of the Blueprint for Patient Safety at the Hospital for Sick Children to identify potential and existing vulnerabilities and failures and put measures in place to avoid and mitigate any harm. Reviewing internal reports and actively seeking vulnerabilities has allowed us to make important changes to improve patient safety at the hospital. In this article, we review four internal surveillance strategies that have been particularly successful in driving change - safety reports, morbidity and mortality reviews, patient safety walkarounds and shoe leather infection control rounds - and discuss the successes and challenges we have experienced.
\end{abstract}

D he Blueprint for Patient Safety at the Hospital for Sick Children (SickKids) is a 10-item road map that has guided the hospital in its active transition to a culture of safety (Stevens et al. 2005). An essential underpinning of the Blueprint is the ongoing need to identify failures, examine their contributing factors and apply the learnings to processes of care improvement and system redesign with the goal of preventing recurrences. This approach reflects two of the main characteristics of a safety culture: reporting (organizational encouragement for staff to report their errors and near misses) and learning (individuals' and groups' willingness and ability to understand and make changes based on the safety information that is provided through the system) (Reason 1997). Explicitly highlighted in the Blueprint are two key components, internal and external surveillance, that is, the search for potential and existing vulnerabilities and failures in order to put measures in place to avoid and mitigate any harm.

Surveillance, "the ongoing systematic collection, analysis and interpretation of healthcare data essential to the planning, implementation, and evaluation of public health practice, 
closely integrated with the timely dissemination of these data to those contributing data or to other interested groups who need to know," is an important tool in the science of epidemiology (Horan and Gaynes 2004). The value of surveillance on process and outcome improvements makes it useful for studies beyond the standard epidemiological focus on disease.

No single method of surveillance is sensitive enough to detect all potential or true adverse events. For example, real-time record review has been more sensitive in the detection of adverse events than was incident reporting. Pharmacy surveillance found additional medication errors, and there was little overlap between the three systems (Olsen et al. 2007). Similarly, surgical site infections were identified more frequently by reviews of antibiotic records and diagnostic codes than by routine methods of surveillance of surgical site infections (Yokoe et al. 2004).

A multi-component strategy in each of the 10 blueprint elements was a key consideration in the blueprint's development. In this article, we review four strategies of internal surveillance that we have used to improve patient safety at SickKids - safety reports, morbidity and mortality (M\&M) reviews, patient safety walkarounds and shoe leather infection control rounds - and discuss the successes and challenges experienced in the course of their implementation.

\section{Safety Reporting System}

Errors, near misses and adverse events are under-reported, particularly by physicians (Taylor et al. 2004). It has been proposed that clarification of the requirements of an incident report, simplification of the process and feedback to the reporters are strategies that could be used to increase reporting (Evans et al. 2006).

In May 2004, a secure web-based safety reporting system with an anonymous reporting feature was implemented at SickKids to support the reporting of potential and actual adverse events in support of our code of conduct, including issues involving patient care (e.g., medication, diagnostics, treatment), occupational health and safety issues, issues involving honesty and integrity, breaches of confidentiality and privacy, issues related to respect, issues related to parents and visitors, environmental hazards and equipment problems. This new system replaced multiple paper-based systems that were limited in their ability to generate reports and identify hospital issues and trends. The purpose of safety reporting is to generate knowledge to support system improvements and not to point fingers or find fault with the practice of individuals. This purpose is stated in a supporting safety reporting policy, which describes the process for reporting, managing and investigating adverse events including the following:

- Ensuring care of the patient, visitor or volunteer

- Ensuring care of staff members

- Creating a report

- Reviewing events - this outlines the responsibilities of the manager or director in following up the event, the responsible physician and other individuals and departments involved (e.g., pharmacy, medical engineering, occupational health)

- Providing oversight, managing the system, generating hospital-wide reports, assisting managers, highlighting reported events that require a critical occurrence review these are responsibilities of the Quality and Risk Management Department

Features of the new safety reporting system include accessibility from all computers in the hospital, ease of reporting, immediate availability of reports to front-line managers for report resolution, identification of trends and opportunities for improvement and support of feedback to patients, families and staff in a timely manner.

Since the introduction of the safety reporting system, the rate of safety reporting has increased dramatically. Table 1 outlines the rates of reporting (adjusted to 1,000 patient-days) for all reports and for breakdowns into medication, patient and other reports. Reporting periods include the baseline year (the 12 months preceding the change) and each of the three years following system implementation. As can be seen, our rates exceed the median of 35 reports per 1,000 patient-days generated by 26 acute care centres (range nine to 95) across the United States using an electronic error reporting system, as

Table 1. Reporting Rates for total, medication, patient and other events reports

\begin{tabular}{|l|c|c|c|c|c|c|c|c|}
\hline Year & $\begin{array}{l}\text { Total } \\
\text { Reports/1,000 } \\
\text { Patient-Days }\end{array}$ & $\begin{array}{l}\text { \% Increase } \\
\text { from Baseline }\end{array}$ & $\begin{array}{l}\text { Medical } \\
\text { Reports/1,000 } \\
\text { Patient-Days }\end{array}$ & $\begin{array}{l}\text { \% Increase } \\
\text { from Baseline }\end{array}$ & $\begin{array}{l}\text { Patient } \\
\text { Reports/1,000 } \\
\text { Patient-Days }\end{array}$ & $\begin{array}{l}\text { \% Increase } \\
\text { from Baseline }\end{array}$ & $\begin{array}{l}\text { Other } \\
\text { Reports/1,000 } \\
\text { Patient-Days }\end{array}$ & $\begin{array}{l}\text { Increase } \\
\text { from Baseline }\end{array}$ \\
\hline Baseline & 32.29 & 11.07 & & 15.44 & & 5.78 & \\
\hline Year 1 & 46.87 & 45 & 12.85 & 16 & 25.37 & 64 & 8.65 & 50 \\
\hline Year 2 & 49.17 & 52 & 13.82 & 25 & 28.39 & 84 & 6.96 & 20 \\
\hline Year 3 & 51.73 & 60 & 13.75 & 24 & 30.68 & 99 & 7.29 & 26 \\
\hline
\end{tabular}


reported by Milch et al. (2006).

In the study by Milch et al. (2006), reports were classified as follows: $34 \%$ non-medication-related clinical, $33 \%$ medication/infusion related, $13 \%$ falls, $13 \%$ administrative and $6 \%$ other. Medication-related reports were the most common types of reports in two other studies $-47 \%$ in a study by Suresh et al. (2004) and 29\% in a study by Nuckols et al. (2007). At SickKids, the most common type of report is the non-medication-related patient report at 59\%, with medication-related reports making up $27 \%$. Falls (a subset of patient reports) account for only a small percentage of reports (Table 2).

Severity codes are often applied to safety and incident reports as a measure of the potential or actual outcome of the event and are used to highlight the event's seriousness and assist in prioritization of system improvements. At SickKids, the introduction of the online system allowed for an eight-level event severity code, including two levels of near-miss events:

1. Event did not reach anyone; potential minor harm (i.e., if it had reached someone, there was potential for minor harm)

2. Event did not reach anyone; potential major harm (i.e., if it had reached someone, there was potential for major harm)

3. Event reached the person; minor or no harm resulted

4. Minor or no harm resulted; potential major harm (i.e., event reached the person - minor or no harm resulted but it could have been very serious)

5. Event resulted in extra observation or monitoring

Table 2. Percentage of total reports by report type

\begin{tabular}{|l|c|c|c|c|}
\hline Year & $\begin{array}{l}\text { Medical } \\
\text { Reports }\end{array}$ & $\begin{array}{l}\text { Patient } \\
\text { Reports }\end{array}$ & $\begin{array}{l}\text { Patient Fall } \\
\text { Reports }\end{array}$ & $\begin{array}{l}\text { Other } \\
\text { Reports }\end{array}$ \\
\hline Baseline & 34 & 48 & - & 18 \\
\hline Year 1 & 27 & 54 & 2.2 & 18 \\
\hline Year 2 & 28 & 58 & 1.9 & 14 \\
\hline Year 3 & 27 & 59 & 1.5 & 14 \\
\hline
\end{tabular}

6. Event resulted in treatment or intervention

7. Event resulted in increased length of stay

8. Event may have contributed to permanent disability or death

Events in levels five through eight are examined further through the M\&M process described later.

Table 3 outlines the breakdown of events by severity code for the three years of system use and the overall average for all events and patient events. This breakdown compares with that in the Milch et al. (2006) study: 13\% near miss, 67\% no harm, 32\% temporary harm, $0.8 \%$ life-threatening or permanent harm and $0.4 \%$ contributing to patient death. Another study reports a $25 \%$ near-miss rate (Taylor et al. 2004).

\section{Absolute numbers are not the goal of a} safety reporting system. The goal is, rather, the identification of areas for improvement.

\section{Examples of Improvements Resulting from Safety Reporting}

"As long as the system receives sufficient reports to identify the main safety issues, the absolute number of reports is not critical; however, to achieve this staff do have to be encouraged to report and to communicate their concerns" (Vincent 2006). As Vincent notes, absolute numbers are not the goal of a safety reporting system. The goal is, rather, the identification of areas for improvement. At SickKids, numerous improvements have resulted from the reporting of actual and potential events, including the following examples:

- Safety reports alerted us to inconsistent practices in intravenous (IV) fluid administration. In a few instances, patients were burned when IV fluid bags warmed in a microwave were used. Following reporting, a new product was purchased that was able to provide the optimal level of warmth without overheating.

Table 3. Severity for all reports and patient reports

\begin{tabular}{|c|c|c|c|c|c|c|c|c|}
\hline \multirow[b]{2}{*}{ Year } & \multicolumn{2}{|c|}{$\begin{array}{l}\text { Near Miss, Potential Harm } \\
\text { Codes } 1 \text { and } 2\end{array}$} & \multicolumn{2}{|c|}{$\begin{array}{l}\text { No or Minor Harm } \\
\text { Codes } 3 \text { and } 4\end{array}$} & \multicolumn{2}{|c|}{$\begin{array}{l}\text { Moderate Harm } \\
\text { Codes 5-7 }\end{array}$} & \multicolumn{2}{|c|}{$\begin{array}{l}\text { Severe Harm } \\
\text { Code } 8\end{array}$} \\
\hline & $\begin{array}{l}\text { All Reports } \\
(\%)\end{array}$ & $\begin{array}{l}\text { Patient } \\
\text { Reports (\%) }\end{array}$ & $\begin{array}{l}\text { All Reports } \\
(\%)\end{array}$ & $\begin{array}{l}\text { Patient } \\
\text { Reports (\%) }\end{array}$ & $\begin{array}{l}\text { All Reports } \\
(\%)\end{array}$ & $\begin{array}{l}\text { Patient } \\
\text { Reports (\%) }\end{array}$ & $\begin{array}{l}\text { All Reports } \\
(\%)\end{array}$ & $\begin{array}{l}\text { Patient } \\
\text { Reports (\%) }\end{array}$ \\
\hline Year 1 & $1,135(27)$ & $612(27)$ & $2,710(65)$ & $1,494(65)$ & 297 (7.2) & $187(8.2)$ & $1(0.02)$ & $1(0.04)$ \\
\hline Year 2 & $1,143(26)$ & $628(25)$ & $2,787(64)$ & 1,608 (64) & $410(9.4)$ & $290(11.5)$ & $2(0.05)$ & $2(0.08)$ \\
\hline Year 3 & $1,014(24)$ & $617(23)$ & $2,760(64)$ & $1,749(64)$ & $535(12.4)$ & 370 (13.5) & $1(0.02)$ & $1(0.04)$ \\
\hline Total & $3,292(26)$ & $1,857(25)$ & $8,257(65)$ & $4,851(64)$ & $1,242(11.2)$ & $847(11.2)$ & $4(0.03)$ & $4(0.04)$ \\
\hline
\end{tabular}


- A report of a patient who locked the door to his room to avoid medication administration led to an audit that identified other patient care areas with lockable doors, ultimately leading to the disengagement of inappropriate locking devices.

- A report on potential patient harm following the inadvertent flushing of an IV with concentrated potassium chloride instead of normal saline led to the widespread removal of this product from the nursing units and the purchase of premixed potassium solutions.

- Safety reports related to construction debris flying off our roof in high winds led to the implementation of a roof surveillance process and the notification of facility staff when third-party contractors require access to the roof.

\section{M\&M Reviews}

$M \& M$ reviews are another important component of internal surveillance at SickKids. Historically, M\&M reviews served as a form of physician peer review, but they have evolved over the years to focus on teaching and improvements in patient care.

At SickKids there is a defined process to ensure multidisciplinary and timely reviews of patient deaths and morbidity events to ensure that the care provided was appropriate and to identify opportunities for improvements in care processes and systems. Mortality events are deaths. Morbidity events are defined as "an untoward event or complication which, under optimal conditions, is not a natural consequence of the patient's disease or treatment" (Craddick and Bader 1983).

All clinical divisions within the hospital are responsible for conducting monthly M\&M reviews of all deaths and significant morbidity events and submitting minutes to the Hospital M\&M Review Committee. More recently, divisions were also charged with reviewing all code blue calls (cardiac or respiratory arrests)

Figure 1. Quarterly summary of the M\&M reviews and targeted safety reports

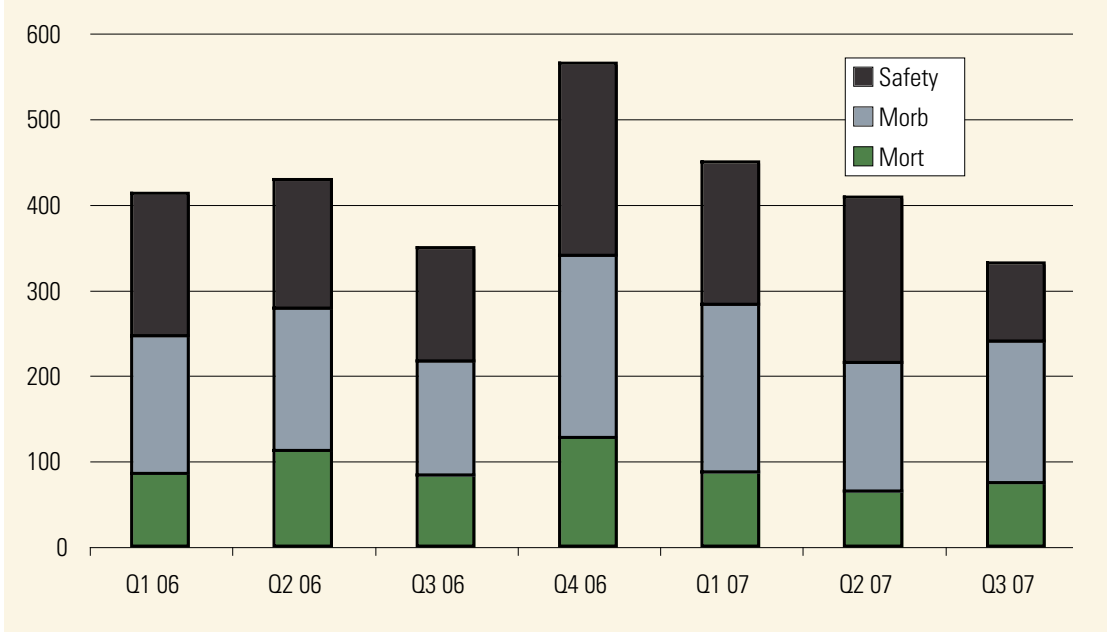

and safety reports specific to the division with severity codes of four (minor or no harm; potential major harm) through eight (may have contributed to permanent disability or death). The Hospital M\&M Review Committee provides oversight for the M\&M review process at SickKids by monitoring the adequacy of M\&M review processes in each division. This hospital committee is responsible for identifying hospital-wide issues and trends, making recommendations regarding issues arising from $M \& M$ reviews and monitoring and reporting compliance with the M\&M policy.

In January 2006 an electronic database was established to track all M\&M reviews and targeted safety reports. Figure 1 shows the quarterly summary of these reviews. In the 21 months since this detailed record keeping was initiated, almost 3,000 reviews have been logged. It should be noted that for each death there are often multiple reviews, reflecting the involvement of a number of services and divisions.

\section{No single method of surveillance is sensitive enough to detect all potential or true adverse events.}

\section{Examples of Improvements Resulting from M\&M Reporting}

Numerous local improvements in the quality and safety of care occur as a result of M\&M reviews. In addition, a number of hospital-wide issues have been addressed or supported as a result of M\&M reporting trends. Issues brought to our attention through this process included (1) problems with timely IV access for patients, following reorganization of resources within the hospital (the issue was reviewed and resources realigned to improve service) and (2) instances of wrong site procedures (which resulted in the timely implementation of a correct procedure/patient/site policy and practice).

\section{Patient Safety Walkarounds}

Patient Safety Leadership WalkRounds as first described by Frankel et al. (2003) engaged a core group of leaders, including senior executive and vice-presidents, who visited different areas of the hospital weekly involving local staff in discussions about recent safety events and the contributing factors involved. Data were recorded, entered into a database, analyzed and used to target improvement efforts. After two years of WalkRounds, 1,433 comments from 233 sessions had been reported: $30 \%$ 
were related to equipment, $13 \%$ to communications, $7 \%$ to pharmacy and 6\% to workforce (Frankel et al. 2005). Although WalkRounds were identified as "effective tool[s] for engaging leadership, identifying safety issues, and supporting a culture of safety," committed leadership and resources available for data management were identified as critical success factors (Frankel et al. 2005).

At Johns Hopkins, the ongoing collaboration between executives and clinical units was established differently. Individual executive members "adopted" an intensive care unit and worked with staff to identify and address patient safety issues (Pronovost et al. 2004). The approach has proven useful in enhancing executive awareness and improving staff trust, as well as in expediting action on issues of concern.

From November 2004 through December 2005, we conducted 15 leadership safety walkarounds (LSWs) in which one or two executive members, quality analysts and the medical director of patient safety visited areas throughout the hospital inquiring about patient and staff safety. Following these 15 LSWs, members of the executive were interviewed to see if they considered LSWs to be a value-added activity. The executive members agreed that LSWs represent an important opportunity for members of senior management to visibly demonstrate their commitment to safety at the hospital. A major deficiency identified was the ambiguous assignation of responsibility for issues raised and the lack of mechanism for prioritization and follow-up. Without adequate follow-up, there was concern that the entire process would lose credibility. In addition, focusing on both staff and patient safety was felt to detract from patient issues, making the recommendations too diffuse and extensive.

On reflection, we realized that no formal mechanism of

Table 4. Categories of issues raised during patient safety walkarounds

\begin{tabular}{|l|c|c|c|c|}
\hline Main Categories & $\begin{array}{l}\text { Clinical Areas: } \\
\text { No. of Issues } \\
\text { Raised }\end{array}$ & $\begin{array}{l}\text { Clinical Areas: } \\
\text { No. of Action } \\
\text { Items }\end{array}$ & $\begin{array}{l}\text { Non-clinical } \\
\text { Areas: No. of } \\
\text { Issues raised }\end{array}$ & $\begin{array}{l}\text { Non-clinical } \\
\text { Areas: No. of } \\
\text { Action Items }\end{array}$ \\
\hline Equipment & 18 & 6 & 5 & 2 \\
\hline Environment & 16 & 4 & & \\
\hline Access/beds & 9 & 4 & & \\
\hline Care/coordination & 9 & 4 & & \\
\hline Infection control & 4 & & & \\
\hline Human resources & & & 4 & 3 \\
\hline Information technology & & & 1 & \\
\hline Documentation & 11 & 12 & 8 & \\
\hline Other & 67 & 30 & 21 & \\
\hline Total & & & & \\
\hline
\end{tabular}

educating clinical directors about the LSWs had occurred and that we lacked hospital-wide buy-in. As a result, a number of changes were made. A presentation was made to the directors, giving them a chance to voice their concerns. We amended the focus of the rounds to patient safety only and renamed them patient safety walkarounds (PSWs). Going forward, we decided that, although we would record all issues arising, two or three issues would be identified for action and have responsibility assigned. Since that time, after a PSW, a summary of the round has been forwarded to the attendees, with action items highlighted and the responsible person noted. A database has been developed and, recently, responsibility for data entry and analysis has been assigned.

\section{Without adequate follow-up, there was concern that the entire process would lose credibility.}

Since January 2006, we have performed and analyzed 15 PSWs, 13 in clinical areas and two in non-clinical areas (pharmacy and medical engineering). Table 4 summarizes the categories of concerns raised and the types of concerns prioritized for improvement. As expected, the concerns in the clinical and non-clinical areas differed.

To date, improvements made as a result of PSWs include modifying light cords to minimize the risk of strangulation; highlighting the correct person, site and procedure policy outside the operating room; installing an emergency telephone in the occupational therapy gym; and acquiring a walkie-talkie system for communication in the large post-operative recovery suite. Most of the recommendations have now been entered into the database, which should facilitate ongoing follow-up.

\section{Shoe Leather Infection Control Rounds}

Recent evidence suggests that, annually, approximately $8 \%$ of children and $10.5 \%$ of adults hospitalized in Canada acquire an infection (Gravel et al. 2007a, 2007 b), amounting to 220,000 nosocomial infections and 8,000 excess deaths per year (Zoutman et al. 2003). Over two decades ago, Hozman used the term shoe leather surveillance to describe 
monthly hospital tours conducted by members of the infection control committee (1983). Subsequently, Weems (1996) reported on a "shoe leather" approach he initiated in which the entire infection control team regularly visited selected clinical areas and reviewed patients in isolation or who had antibioticresistant organisms, as well as ad hoc practice-related issues. The perceived benefits of the rounds were the opportunities for education, real-time feedback and intervention and collaboration. Although electronic health records and computerized microbiology and pharmacy records have the potential to make walkaround surveillance obsolete, the opportunity to liaise face to face with front-line staff offers many of the advantages described above for PSWs.

The infection control audit is another shoe leather technique that complements routine surveillance practices. By searching for practices that breach infection prevention and control standards, measures can be taken pre-emptively to avoid the development of nosocomial infections. In Vancouver, Bryce and colleagues have developed an audit process incorporating a review of the physical layout and protocols and policies, an assessment of healthcare workers' knowledge of infection control principles and a review of workplace practices (Bryce et al. 2007). Others have used an audit process to assess the efficacy of environmental cleaning (Malik et al. 2003).

Harkening to Weems's (1996) "A Plea from the Sole: Let's Keep the 'Shoe Leather' in Healthcare Epidemiology," we initiated shoe leather infection control rounds, fondly known as SLIC rounds in June 2006; by October 2007, we had done 14 rounds. All members of the infection prevention and control team who are available at the scheduled time, including trainees, participate. It is thus an opportunity for observing and teaching, real-time feedback and facilitation of improvement activities. SLIC rounds are pre-scheduled. As a rule, a manager or other staff member in the area under review accompanies our group. However, the topic for the round is not necessarily geographically based; it may instead be thematic, for example, the status of the breast pump rooms, availability of hand hygiene dispensers or posted list of reportable communicable diseases. Soon after the completion of a round, a summary of recommendations is forwarded to the manager - on average, there are 10 recommendations (range two to 52). The following are the most commonly identified issue topics:

- Appropriate placement, installation and maintenance of waterless gel

- Hand hygiene and respiratory etiquette signage

- Storage of supplies and equipment

- Use of corrugated cardboard in high-risk patient care areas

- Presence of food in patient care areas

- Expiry of supplies

We estimate that approximately $75 \%$ of the recommen- dations have been effected to date, although an item-by-item follow-up by the infection control team is not carried out. SLIC rounds are collaborative exercises in which we share our expertise with the front-line people responsible for patient care. Done in the spirit of improvement, we feel these rounds are collegial and perceived as being less "top down" than other audits. They also afford each infection control practitioner an opportunity to apprise the other teammates of issues of concern in their area of coverage, thus creating a learning opportunity. A telling sign of the success of these rounds has been the voluntary participation of at least two infection control practitioners on each SLIC round.

\section{Our multi-faceted internal surveillance program has demonstrated to us that the detection of hazards and vulnerabilities in hospitals is enhanced when multiple strategies are used.}

\section{Discussion}

Our multi-faceted internal surveillance program has demonstrated to us that the detection of hazards and vulnerabilities in hospitals is enhanced when multiple strategies are used. We were able to identify issues with some processes (e.g., communication in the post-operative recovery suite) that would not have been picked up through the other reviews. In our hands, the combination of both active surveillance (trained personnel vigorously looking, i.e., the PSWs and SLIC rounds) and passive surveillance (the reviewing of reports submitted by others, i.e., safety reports and M\&M reviews) maximized the detection of potential or real safety hazards or events and provided more opportunities to effect change. Furthermore, the types of active surveillance we used facilitated real-time input and remediation, which contrasts the response to events identified by retrospective review.

In considering what surveillance strategies best suit the needs of a given healthcare environment, it is important to recognize that analysis and feedback of the data are integral components of surveillance and necessary to improve patient safety. With the assumption that the collection of any relevant data can inform improvements and influence patient outcomes, we recommend asking the following questions when deciding what surveillance strategy(s) to undertake:

- What is the scope of vulnerabilities that we are interested in? For example, are we interested in all hazards or in select ones (e.g., medication related)? and do we want hospital-wide data or data from one area only (e.g., intensive care unit)?

- Have we sought stakeholder input? For example, are the executives prepared to do PSWs? 
Table 5. Attributes of various surveillance methodologies

\begin{tabular}{|l|l|l|l|l|}
\hline & $\begin{array}{l}\text { Safety Reporting } \\
\text { System }\end{array}$ & $\begin{array}{l}\text { Morbidity and } \\
\text { Mortality Review }\end{array}$ & $\begin{array}{l}\text { Patient Safety } \\
\text { Walkarounds }\end{array}$ & $\begin{array}{l}\text { Shoe Leather } \\
\text { Infection Control } \\
\text { Rounds }\end{array}$ \\
\hline $\begin{array}{l}\text { Scope of vulnerabilities } \\
\text { detected }\end{array}$ & $\begin{array}{l}\text { Hospital wide, all } \\
\text { hazards }\end{array}$ & $\begin{array}{l}\text { Hospital wide, all } \\
\text { hazards }\end{array}$ & $\begin{array}{l}\text { Hospital wide, all } \\
\text { hazards }\end{array}$ & $\begin{array}{l}\text { Hospital wide, } \\
\text { infection control } \\
\text { hazards only }\end{array}$ \\
\hline $\begin{array}{l}\text { Real-time data collection } \\
\text { and analysis }\end{array}$ & No & No & Yes & Yes \\
\hline $\begin{array}{l}\text { Retrospective data } \\
\text { analysis }\end{array}$ & Yes & Yes & No & No \\
\hline Personnel requirement & $\begin{array}{l}\text { Input by personnel } \\
\text { throughout hospital, } \\
\text { data analyzer needed }\end{array}$ & Committee & $\begin{array}{l}\text { Small team including } \\
\text { executive member }\end{array}$ & $\begin{array}{l}\text { Infection control } \\
\text { practitioner(s) and } \\
\text { unit director }\end{array}$ \\
\hline $\begin{array}{l}\text { Information technology } \\
\text { requirement }\end{array}$ & $\begin{array}{l}\text { Not necessary but } \\
\text { facilitates input and } \\
\text { analysis }\end{array}$ & $\begin{array}{l}\text { Not necessary but } \\
\text { facilitates tracking } \\
\text { of actions arising }\end{array}$ & $\begin{array}{l}\text { Not necessary but } \\
\text { facilitates tracking of } \\
\text { actions arising }\end{array}$ & $\begin{array}{l}\text { Not necessary but } \\
\text { facilitates tracking } \\
\text { of actions arising }\end{array}$ \\
\hline
\end{tabular}

the completion of any single recommended action item; however, it is the feedback to the reporter that perpetuates the influx of information and closes the loop" (2005).

The sustainability of any of these strategies is influenced by their real (e.g., fulfilling a legislative requirement) and perceived (e.g., executive becomes engaged in PSWs) values, which may subsequently affect the resources allocated. All strategies work best within

- Are certain data collections mandated (i.e., by hospital policy, accreditation or legislation)?

- Do we plan to collect the data in real time (which facilitates timely intervention but is time consuming) or retrospectively (which is good for trend analysis and can be collected when convenient)?

- What resources (personnel, content expertise, information technology, finances, etc.) are or can be made available to us for data collection, analysis, feedback and improvement? Can we leverage the resources of another department (e.g., get data regarding medical equipment from medical engineering)?

- What methods of surveillance will we be able to sustain over time?

Table 5 applies many of these considerations to the four methods of surveillance we use at SickKids.

Our experience is consistent with that of other investigators, who highlight the importance of follow-up and feedback to ensure practice and process improvement and sustain credibility in the institution's commitment to a culture of safety. In this context, follow-up includes prioritizing opportunities and actions, assigning responsibility and accountability and implementing the action plan; and feedback facilitates closing the loop, responding to those who reported the issue and communicating to the rest of the hospital staff and clinicians about the events and actions taken (Ghandi et al. 2005). A critical success factor is the ability to efficiently track issues and provide timely feedback. As noted by Ghandi et al., "Developing and maintaining a systematic method for feedback represents more of a challenge than a culture of safety, where a sense of justice and fairness prevails and where healthcare workers do not fear "shame and blame" if they report a hazard or mishap (Senge 2006). A culture of safety thrives best in a learning organization "where people continually expand their capacity to create the results they truly desire, where new and expansive patterns of thinking are nurtured, where collective aspiration is set free, and where people are continually learning how to learn together" (Connor et al. 2007). However, even in its absence, surveillance for hazards can actually foster a culture of safety if the data heighten awareness and lead to change. Data derived through surveillance activities will likely reveal problems with the system rather than with particular individuals. Indeed system improvements are the key to safer healthcare. $\mathrm{HQ}$

\section{About the Authors}

Anne Matlow, MD, FRCPC, is medical director of patient safety and director of the Infection Prevention and Control Programme, the Hospital for Sick Children, Toronto, Ontario. You can contact her at 416-813-5996, by fax at 416-813-4992 or by e-mail at anne.matlow@sickkids.ca.

Polly Stevens, MHSc, is director of quality and risk management, the Hospital for Sick Children.

Lynn Urmson, RN, BA, is associate risk manager, Department of Quality and Risk Management, the Hospital for Sick Children.

Rick Wray, BScN, ClC, is manager of the Infection Prevention and Control Programme, the Hospital for Sick Children. 


\section{References}

Bryce, E.A., S. Scharf, M. Walker and A. Walsh. 2007. "The Infection Control Audit: The Standardized Audit as a Tool for Change." American Journal of Infection Control 35(4): 271-83.

Connor, M., D. Duncombe, E. Barclay, S. Bartel, C. Borden, E. Gross, C. Miller and P.R. Ponte. 2007. "Creating a Fair and Just Culture: One Institution's Path toward Organizational Change." Joint Commission Journal on Quality and Patient Safety 33(10): 617-24.

Craddick, J.W. and B.S. Bader. 1983. Medical Management Analysis, A Systematic Approach to Quality Assurance and Risk Management (Vol. I). Auburn, CA: JW Craddick.

Evans, S.M., J.G. Berry, B.J. Smith, A. Esterman, P. Selim, J. O'Shaughnessy and M. DeWit. 2006. "Attitudes and Barriers to Incident Reporting: A Collaborative Hospital Study." Quality and Safety in Health Care 15(1): 39-43.

Frankel, A., E. Graydon-Baker, C. Neppl, T. Simmonds, M. Gustafson and T.K. Gandhi. 2003. "Patient Safety Leadership WalkRounds." Joint Commission Journal on Quality and Safety 29(1): 16-26.

Frankel, A., S.P. Grillo, E.G. Baker, C.N. Huber, S. Abookire, M. Grenham, P. Console, M. O'Quinn, G. Thibault and T.K. Gandhi. 2005. "Patient Safety Leadership WalkRounds at Partners Healthcare: Learning from Implementation." Joint Commission Journal on Quality and Patient Safety 31(8): 423-37.

Friedman, J.N., M.S. Pinard and R.M. Laxer. 2005. “The Morbidity and Mortality Conference in University-Affiliated Pediatric Departments in Canada." Journal of Pediatrics 146(1): 1-2.

Gandhi, T.K., E. Graydon-Baker, C.N. Huber, A.D. Whittemore and M. Gustafson. 2005. "Closing the Loop: Follow-Up and Feedback in a Patient Safety Program." Joint Commission Journal on Quality and Patient Safety 31(11): 614-21.

Gravel, D., A. Matlow, M. Ofner-Agostini, M. Loeb, L. Johnston, E. Bryce, M.L. Sample, V.R. Roth, C. Goldman, G. Taylor and the Canadian Nosocomial Infection Surveillance Program. 2007a. "A Point Prevalence Survey of Health Care-Associated Infections in Pediatric Populations in Major Canadian Acute Care Hospitals." American Journal of Infection Control 35(3): 157-62.

Gravel, D., G. Taylor, M. Ofner, L. Johnston, M. Loeb, V.R. Roth, J. Stegenga, E. Bryce and the Canadian Nosocomial Infection Surveillance Program. 2007b. "Point Prevalence Survey for Healthcare-Associated Infections within Canadian Adult Acute-Care Hospitals." The Journal of Hospital Infection 66(3): 243-8.

Horan, T.C. and R.P. Gaynes. "Surveillance of Nosocomial Infections." In C.G. Mayall, ed., Hospital Epidemiology and Infection Control (3rd ed). Philadelphia, PA: Lippincott Williams and Williams.

Hozman, S. 1983. "Shoe Leather Surveillance: Monthly Hospital Tours Conducted by Infection Control Committee Members." American Journal of Infection Control 11(3): 34A-5A.

Malik, R.E., R.A. Cooper and C.J. Griffith. 2003. "Use of Audit Tools to Evaluate the Efficacy of Cleaning Systems in Hospitals." American Journal of Infection Control 31(3): 181-7.

Milch, C.E., D.N. Salem, S.G. Pauker, T.G. Lundquist, S. Kumar and J. Chen. 2006. "Voluntary Electronic Reporting of Medical Errors and Adverse Events. An Analysis of 92,547 Reports from 26 Acute Care Hospitals." Journal of General Internal Medicine 21(2): 165-70.

Nuckols, T.K., D.S. Bell, H. Liu, S.M. Paddock and L.H. Hilborne. 2007. "Rates and Types of Events Reported to Established Incident Reporting Systems in Two US Hospitals." Quality and Safety in Health Care 16(3): 164-8.
Olsen, S., G. Neale, K. Schwab, B. Psaila, T. Patel, E.J. Chapman and C. Vincent. 2007. "Hospital Staff Should Use More than One Method to Detect Adverse Events and Potential Adverse Events: Incident Reporting, Pharmacist Surveillance and Local Real-Time Record Review May All Have a Place." Quality and Safety in Health Care 16(1): 40-4.

Pronovost, P.J., B. Weast, K. Bishop, L. Paine, R. Griffith, B.J. Rosenstein, R.P. Kidwell, K.B. Haller and R. Davis. 2004. "Senior Executive Adopt-a-Work Unit: A Model for Safety Improvement." Joint Commission Journal on Quality and Safety 30(2): 59-68.

Reason, J. 1997. Managing the Risks of Organizational Accidents. Brookfield, VT: Ashgate.

Senge, P.M. 2006. The Fifth Discipline: The Art and Practice of the Learning Organization. New York: Doubleday.

Stevens, P., A. Matlow and R. Laxer. 2005. "Building from the Blueprint for Patient Safety at the Hospital for Sick Children." Healthcare Quarterly 8: 132-9.

Suresh, G., J.D. Horbar, P. Plsek, J. Gray, W.H. Edwards, P.H. Shiono, R. Ursprung, J. Nickerson, J.F. Lucey and D. Goldmann. 2004. "Voluntary Anonymous Reporting of Medical Errors for Neonatal Intensive Care." Pediatrics 113(6): 1609-18.

Taylor, J.A., D. Brownstein, D.A. Christakis, S. Blackburn, T.P. Strandjord, E.J. Klein and J. Shafii. 2004. "Use of Incident Reports by Physicians and Nurses to Document Medical Errors in Pediatric Patients." Pediatrics 114(3): 729-35.

Vincent, C. 2006. Patient Safety. Edinburgh: Churchill Livingston, Elsevier Ltd.

Weems, J.J., Jr. 1996. "A Plea from the Sole: Let's Keep the 'Shoe Leather' in Healthcare Epidemiology.” Infection Control and Hospital Epidemiology 17(1): 42-3.

Yokoe, D.S., G.A. Noskin, S.M. Cunningham, G. Zuccotti, T. Plaskett, V.J. Fraser, M.A. Olsen, J.I. Tokars, S. Solomon, T.M. Perl, S.E. Cosgrove, R.S. Tilson, M. Greenbaum, D.C. Hooper, K.E. Sands, J. Tully, L.A. Herwaldt, D.J. Diekema, E.S. Wong, M. Climo and R. Platt. 2004. "Enhanced Identification of Postoperative Infections among In-Patients.” Emerging Infectious Diseases 10: 1924-30.

Zoutman, D.E., B.D. Ford, E. Bryce, M. Gourdeau, G. Hébert, E. Henderson and S. Paton; Canadian Hospital Epidemiology Committee, the Canadian Nosocomial Infection Surveillance Program and Health Canada. 2003. "The State of Infection Surveillance and Control in Canadian Acute Care Hospitals." American Journal of Infection Control 31(5): 266-72. 